\title{
Abordagem Qualitativa sobre Informações da Controladoria Divulgadas nos Websites Institucionais de Empresas Listadas na B3
}

Qualitative Approach on Controlling Information Disclosed on the Institutional Websites of Companies Listed on B3

Enfoque Cualitativo Sobre La Información De La Contraloría Divulgada En Los Sitios Web Institucionales De Las Empresas Incluidas En B3

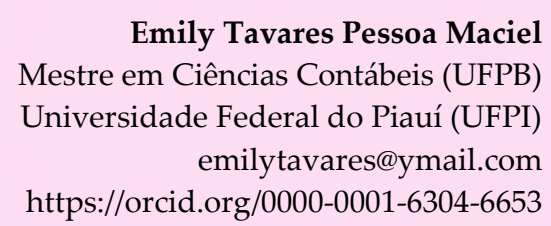

Emily Tavares Pessoa Maciel Mestre em Ciências Contábeis (UFPB) emilytavares@ymail.com https://orcid.org/0000-0001-6304-6653

\author{
Antônio André Cunha Callado \\ Doutor em Administração (UFPB) \\ Universidade Federal Rural de Pernambuco \\ (UFRPE) \\ andrecallado@yahoo.com.br \\ https://orcid.org/0000-0002-5704-9265
}

\section{RESUMO}

Objetivo: evidenciar a divulgação de informações sobre controladoria a partir de uma abordagem qualitativa no âmbito dos websites institucionais das empresas listadas na Brasil, Bolsa e Balcão (B3).

Método: para a consecução deste objetivo foi realizada uma pesquisa exploratória, descritiva e qualitativa. Para a coleta das informações referentes à evidenciação de controladoria foram considerados todos os conteúdos disponibilizados nos websites institucionais das 426 empresas listadas considerando um checklist de informações pontuadas como importantes e fazendo uso da técnica da análise de conteúdo nos documentos disponibilizados pelas empresas para identificar a vinculação da controladoria na estrutura organizacional e o local de divulgação.

Principais resultados: a partir dos resultados obtidos foi percebido que a controladoria está vinculada tanto aos órgãos da alta administração, quanto ao nível gerencial. Com relação ao local onde foi possível identificar informações sobre a controladoria, merecem destaque os formulários de referência, de forma solta e não agrupada.

Contribuições: há pouco detalhamento por parte das organizações do local e de mais explicações sobre a controladoria, grande parte das informações encontradas foram extraídas dos formulários de referência.

Relevância: a controladoria não está só relacionada à alta gestão como visto em trabalhos anteriores, percebe-se uma crescente vinculação da controladoria ao nível gerencial das organizações.

Palavras-chave: Controladoria. Evidenciação. Unidade organizacional. 
Emily Tavares Pessoa Maciel; Antônio André Cunha Callado.

\section{ABSTRACT}

Objective: to demonstrate the disclosure of information about controllership from a qualitative approach within the institutional websites of companies listed in Brazil, Bolsa and Balcão (B3).

Method: to achieve this objective, an exploratory, descriptive and qualitative research was carried out. For the collection of information regarding the disclosure of controllership, all content available on the institutional websites of the 426 listed companies was considered, using a checklist of information scored as important and the technique of content analysis in the documents provided by the companies to identify the link of the controllership in the organizational structure and the place of dissemination.

Main results: based on the results obtained, it was noticed that controllership is linked to both the senior management bodies and the managerial level. Regarding the place where it was possible to identify information about the controllership, the reference forms, in loose form and not grouped, deserve to be highlighted.

Contributions: there is little detail on the part of local organizations, moreover there's a lack of detail on controllership, much of the information found was extracted from the reference forms.

Relevance: controllership is not only related to senior management, as seen in previous works, since it's noticeable that there is a growing link between controllership and the managerial level of organizations.

Keywords: Controllership. Disclosure. Organization unit.

\section{RESUMEN}

Objetivo: demostrar la divulgación de información sobre la contraloría desde un enfoque cualitativo dentro de los sitios web institucionales de las empresas cotizadas en Brasil, Bolsa y Balcão (B3).

Método: para lograr este objetivo se realizó una investigación exploratoria, descriptiva y cualitativa. Para la recolección de información sobre la divulgación de la contraloría, se consideró todo el contenido disponible en los sitios web institucionales de las 426 empresas cotizadas, considerando una lista de verificación de información calificada como importante y utilizando la técnica de análisis de contenido en los documentos proporcionados por las empresas para identificar el vínculo de la contraloría en la estructura organizativa y la ubicación de la información publicada.

Principales resultados: a partir de los resultados obtenidos, se constató que la contraloría está vinculada tanto a los órganos de alta dirección como al nivel gerencial. En cuanto a la ubicación fue posible identificar información sobre la contraloría, los formularios de referencia, en forma suelta y no agrupados, merecen ser destacados.

Contribuciones: hay pocos detalles por parte de las organizaciones locales y más explicaciones sobre la contraloría, gran parte de la información encontrada fue extraída de los formularios de referencia.

Prosppectus - Perspectivas Qualitativas em Contabilidade e Organizações. João Pessoa. v. 1, n. 1, p. 57 $71, \mathrm{jul} / 2021$. 
Emily Tavares Pessoa Maciel; Antônio André Cunha Callado.

Relevancia: La contraloría no solo está relacionada con la alta dirección, como se vio en trabajos anteriores, existe un vínculo creciente entre la contraloría y el nivel gerencial de las organizaciones.

Palabras clave: Contraloría. Divulgar. Unidad de organización.

\section{INTRODUÇÃO}

As empresas almejam, cada vez mais, controlar suas ações, a fim de acompanhar o trajeto para que se atinja os seus objetivos. Com o intuído de errarem cada vez menos, obterem sucesso e atenderem a todos os pedidos dos gestores, desenvolveu-se a controladoria, que vem assumindo papéis cada vez mais importantes no contexto organizacional, papéis de gerenciamento, avaliação, comunicação, controle e de apoio à alta gestão das empresas (Padoveze, 2013).

A controladoria surgiu de uma forma complementar à contabilidade tradicional, que já era praticada pelas organizações, possibilitando que fossem atendidas as necessidades da alta gestão, focando na interação contínua dos setores que fazem parte da organização e auxiliando a sua sobrevivência (Amorim, Oliveira, Manzi \& Bemfica, 2018). O interesse constante de êxito, juntamente com o avanço tecnológico tem impulsionado a controladoria a adentrar no contexto organizacional. A controladoria estipula que as organizações estimulem as suas metas, tracem os caminhos necessários para que se atinjam essas metas e posteriormente externem a todos que fazem parte das organizações quais foram os objetivos e propósitos propostos, de forma objetiva e clara, facilitando a gestão (Nascimento \& Reginato, 2013; Souza, Nobre, Padoveze \& Calil, 2016).

Frezatti, Rocha, Nascimento e Junqueira (2009) discorrem que a controladoria funciona exercendo um papel de assessoria dentro das organizações. Beuren, Gomes e Luz (2012) apontam que a controladoria é motivada a ser incluída nas organizações frente à melhoria dos processos de gestão e a eficácia do sistema de informações, com o propósito final de atender aos interesses da empresa. Tung (2016) complementa que para que as empresas atinjam tais objetivos, elas precisam utilizar das metodologias que proporcionem a elas organização, medição e avaliação dos seus produtos ou serviços ofertados, por isso, recorrem à controladoria.

Barreto (2008) aponta que um outro fator impulsionador para a formação do órgão controladoria dentro das organizações foi a crescente complexidade das empresas, que impulsionou para que os executivos que ocupavam níveis hierárquicos superiores se afastassem das operações rotineiras e se concentrassem na visão estratégica da empresa, proporcionando informações mais precisas e pertinentes aos stakeholders.

Desempenhando inúmeros papéis na organização, a controladoria tem contemplado diversos estudos e envolvido uma série de pesquisadores a fim de compreender ainda mais o assunto. Para Borinelli (2006), controladoria pode ser entendida a partir de três perspectivas: a) como ramo do conhecimento (aspectos conceituais); b) como conjunto de atividades, funções e artefatos (aspectos Prosppectus - Perspectivas Qualitativas em Contabilidade e Organizações. João Pessoa. v. 1, n. 1, p. 57 $71, \mathrm{jul} / 2021$. 
Emily Tavares Pessoa Maciel; Antônio André Cunha Callado.

procedimentais); c) como órgão do sistema formal organizacional das entidades (aspectos organizacionais).

Reconhecida a importância da controladoria como uma unidade organizacional nas entidades, objetiva-se evidenciar onde encontra-se a divulgação de informações sobre controladoria e qual a vinculação de tal unidade aos outros órgãos/setores que fazem parte do contexto organizacional a partir de uma abordagem qualitativa no âmbito dos websites institucionais das empresas listadas na Brasil, Bolsa e Balcão (B3).

\section{REVISÃO DE LITERATURA}

\subsection{Controladoria}

A ideia inicial de controle de gestão desenvolveu-se desde a década de 60, tomando como base a contabilidade, desde então o assunto passou a ser estudado e evidenciado no interior das organizações (Tambosi, Tambosi Júnior, Hein \& Kroenke, 2021).

Anagusko, Araki e Moser (2020) apontam que a Revolução Industrial e o surgimento de grandes corporações fizeram com que estruturas muito complexas fossem criadas, exigindo da alta gestão um controle mais efetivo dos seus departamentos e divisões, fomentando assim o surgimento da controladoria.

Apesar do estudo constante a controladoria busca incessantemente pela sua própria identidade e pela sua definição clara, que ainda não foi possível atingir (Bermudo \& Vertamatti, 2016).

Para Lima, de Luca, Santos e Pontes (2011), a controladoria tem como propósito assegurar a eficácia empresarial fornecendo informações que sirvam para auxiliar a tomada de decisão dos gestores, possibilitando resultados econômicos mais promissores para as organizações. Viu-se com o passar dos anos, o quão essencial é a controladoria para a sobrevivência, crescimento e para a consolidação das organizações (Morange \& Jorge, 2008).

A controladoria exerce um papel principal no desenvolvimento da gestão efetiva e eficiente das entidades. Para Coelho, Lunkes e Machado (2012) ela funciona como elemento essencial para o processo de gestão frente aos pressupostos básicos que se baseiam a contabilidade.

Padoveze (2016) aponta que a controladoria é o departamento constituído com a responsabilidade de elaborar, implementar e manter os sistemas de informações financeiras, operacionais e contábeis de uma entidade.

As entidades possuem características distintas, por isso a controladoria por elas adotadas, precisam moldar-se às suas especificidades, precisando por vezes moldar-se ao contexto externo e interno a que fazem parte. Implementar as práticas de controladoria nas organizações é uma característica do contexto em que a organização está inserida (Leite, Diehl \& Manvailer, 2015). 
Emily Tavares Pessoa Maciel; Antônio André Cunha Callado.

O surgimento de novas tecnologias, a alta competitividade entre as empresas e a exigência vinda por parte dos consumidos tem feito com que as organizações precisem se adaptar e exigido que a controladoria de tais empresas exerçam essa função de direcionamento, relacionando tanto os fatores internos quanto os fatores externos das empresas (Leite, Reif \& Lavarda, 2018).

A visão contemporânea da controladoria infere que é uma área nas organizações que objetiva a eficiência dos processos internos e externos da gestão, permitindo que todos os usuários tenham acesso às informações necessárias para a tomada de decisão da gestão (Tambosi, Tambosi Júnior, Hein \& Kroenke, 2021).

Schmidt, Santos e Martins (2014) apontam que o profissional responsável por exercer as funções de controladoria é conhecido como controller, que exerce funções dentro da organização capazes de satisfazer as necessidades de seus superiores, englobando informações sobre fornecedores, recursos financeiros, tecnológicos e quaisquer outros, necessários para que a organização atinja sua meta.

Os controllers são os profissionais responsáveis pela controladoria nas organizações, controladoria essa, que segundo Nascimento, Rosa, Santos e Tenório (2005) é um órgão da empresa que possui estrutura funcional formada por técnicas e conceitos que objetivam a geração de informações que sejam necessárias e úteis para a tomada de decisão dos gestores.

A controladoria analisa os dados para conseguir pontuar quais os ramos que as organizações precisarão seguir para atingir o seu sucesso empresarial. Vê-se que a controladoria não tem apenas o intuito de fornecer informações para a entidade, mas tem o propósito de ofertar informações que sejam fidedignas e tempestivas (Araújo, 2003).

Peleias (2002) complementa que a controladoria é uma área presente nas organizações que tem autoridade suficiente para tomar decisões acerca de transações, eventos e atividades exercidas em todo o contexto organizacional.

Para Callado e Amorim (2017) a controladoria abarca informações de natureza operacional, estratégica, econômica, financeira e patrimonial, não se limitando a uma ou outra informação.

A controladoria exerce um papel fundamental no controle e observação dos fatos que ocorrem na organização, pontuando sobre as situações presentes e estimando as situações futuras que poderão colocar em risco a rentabilidade de tal organização, porém, é possível perceber que há ainda um bloqueio na execução da controladoria nas pequenas empresas, que normalmente tendem a não contar com profissionais que tratem exclusivamente da controladoria, e as funções pertencentes aos controllers tendem a ser executada pelos proprietários das empresas (Araújo, 2003; Tung, 2016).

Apesar da disseminação presente do conceito e aplicação da controladoria, o termo em si ainda não foi completamente definido na literatura, mas há um consenso entre os autores sobre os seus objetivos, missões e funções (Politelo, Guse, Leite, Silva \& Door, 2014).

Prosppectus - Perspectivas Qualitativas em Contabilidade e Organizações. João Pessoa. v. 1, n. 1, p. 57 71, jul/2021. 
Emily Tavares Pessoa Maciel; Antônio André Cunha Callado.

A controladoria tem a missão de garantir que os objetivos das organizações sejam cumpridos, através da geração de informações fidedignas e relevantes, com o propósito de otimizar os processos e trazer melhores resultados econômicos para as organizações (Amorim, Oliveira, Manzi \& Bemfica, 2018).

Para Schmidt, Santos e Martins (2014) a função primária da controladoria é a de garantir as informações necessárias para que os gestores tomem decisões fundamentadas e condizentes com os objetivos definidos pela administração.

Uma outra vertente para a missão da controladoria é apontada por Padoveze (2016) que infere que é a de oferecer suporte informacional à alta gestão, objetivando a potencialização dos resultados da organização, a minimização dos riscos, o aproveitamento das oportunidades e respeitando as limitações das organizações, utilizando o sistema contábil disponível pela organização em sua plenitude, para atingir as metas delimitadas pela organização.

Com relação às funções da controladoria, Nascimento e Reginato (2015) constataram que a controladoria exerce a função de promover o monitoramento e a execução dos objetivos que foram estabelecidos, verificando erros e suas possíveis correções, com o intuito de assegurar que as metas que foram admitidas pela alta gestão sejam atingidas.

Carraro e Santanna (2017) complementam que a controladoria tem extrema importância para as organizações, por conseguir atender aos anseios de informações tempestivas para os stakeholders.

De forma geral, a controladoria objetiva atender aos anseios dos gestores e suas funções e missões circundam sobre tais propósitos, de forma geral, de promoção da eficácia das decisões organizacionais, investigando e diagnosticando os resultados obtidos e indicando possíveis correções (Nascimento \& Reginato, 2015).

Tem-se que a função básica da controladoria é o apoio ao processo decisório, fazendo uso de dados e informações disponíveis para facilitar o controle das operações da organização. Araújo (2003) detalhou as funções e disse que o subsídio ao processo, apoio à avaliação de desempenho, avaliação do resultado, gestão dos sistemas de informação, atendimento aos agentes do mercado, apoio no planejamento, na execução dos planos, controle das ações, na avaliação dos resultados e ainda apoio à avaliação de desempenho, comtemplam o leque de funções da controladoria.

\section{METODOLOGIA}

\subsection{Tipologia da pesquisa}

Em busca de uma compreensão mais ampla acerca do local de vinculação, a que órgão/setor está associada a unidade organizacional da controladoria e a localização, em quais documentos disponibilizados pelas empresas existem informações sobre a 
Emily Tavares Pessoa Maciel; Antônio André Cunha Callado.

controladoria nas organizações que fazem parte da Brasil, Bolsa e Balcão (B3) a presente pesquisa se caracteriza como exploratória, descritiva, documental e qualitativa, respondendo ao questionamento proposto.

\subsection{Delimitação e universo da pesquisa}

Para a operacionalização desta pesquisa foram consideradas todas as 426 empresas listadas no site da B3, na época de execução da pesquisa, que foi de junho a setembro de 2019. Sabe-se que o quantitativo de empresas que fazem parte da B3 oscila constantemente frente à saída e entrada de empresas, então, em junho obteve-se o quantitativo e a listagem de todas as empresas que faziam parte da B3 naquele período e focou-se em analisar cada uma delas. Na coleta de dados foi possível buscar informações sobre o objetivo proposto na pesquisa.

\subsection{Instrumento e procedimento de coleta de dados}

Objetivando atingir o propósito da pesquisa, foi elaborado um checklist, com as informações requeridas pela pesquisa, apontamentos que tratavam do local de vinculação/associação da unidade organizacional de controladoria, e interrogações quanto aos documentos que disponibilizavam informações sobre a controladoria de forma geral. Posteriormente foi feita a análise, contemplando as informações pontuadas como essenciais, em todos os documentos e formulários disponibilizados pelas empresas nos seus sítios institucionais, Formulário de Referência, Relatório de Sustentabilidade, Relatório Anual, como também todos os documentos que estão inseridos no site da B3, documentos contemplados na aba de "Relatórios Estruturados", "Informações Relevantes", "Eventos Corporativos" dentre outros documentos lá externados, objetivando encontrar informações que relatassem detalhes sobre a controladoria de cada empresa pesquisada.

O período de coleta dos dados para a análise foi de junho a setembro de 2019.

\subsection{Método de análise}

Foram analisados todos os documentos disponibilizados pelas 426 organizações nos seus websites institucionais como também os formulários de referência, sempre os mais recentes, expostos no site da B3. Todos os dados foram organizados em planilhas do Excel e analisados um a um.

A técnica de análise utilizada para que fosse possível atingir o objetivo da pesquisa foi a análise de conteúdo. Para Martins e Theóphilo (2016) a análise de conteúdo é a técnica utilizada quando se deseja estudar e analisar a comunicação de maneira objetiva e sistemática, com o propósito de identificar a essência de um texto nos detalhes das informações manifestadas pelo texto. 
Emily Tavares Pessoa Maciel; Antônio André Cunha Callado.

Objetivou-se, através da metodologia exposta identificar onde a controladoria está inserida no contexto organizacional, qual seu órgão de vinculação, como também identificar os locais, formulários de referência, relatório anual, relatórios de sustentabilidade, ou outros, utilizados pelas organizações para informar detalhes da controladoria. Na pesquisa, foram analisados todos os sítios institucionais das empresas listadas na B3, todos os documentos lá inseridos e todas as informações identificadas como úteis para a pesquisa. As análises nos documentos disponibilizados pelas empresas foram realizadas entre junho e setembro de 2019.

\section{APRESENTAÇÃO E ANÁLISE DOS RESULTADOS}

Em busca de conhecer mais detalhes sore a unidade organizacional da controladoria referente às 426 empresas listadas na B3, os conteúdos completos de seus respectivos sítios institucionais foram submetidos a uma análise exploratória prospectiva inicial que identificou a divulgação de informações sobre controladoria em apenas 220 delas. Nesta análise foram consideradas duas perspectivas distintas: a) vinculação da controladoria na estrutura organizacional das empresas; b) localização da informação.

Com relação à vinculação da controladoria dentro da estrutura organizacional das empresas listadas na B3, a partir da análise dos conteúdos dos sítios institucionais revelou que foram encontradas distintas vinculações organizacionais da controladoria no interior das empresas. Foram encontradas evidenciações de vinculações da controladoria junto à Presidência, Vice-Presidência e ao Conselho de administração de diversas empresas.

Para a International Meal Company Alimentação S.A. a controladoria é responsável por:

\footnotetext{
"Atuar em conjunto com o Diretor Presidente e o Diretor Administrativo e Financeiro para o desenvolvimento e realização dos objetivos da Companhia."
}

INTERNATIONAL MEAL COMPANY ALIMENTACAO S.A.

A Azul S/A, trouxe ainda a seguinte informação:

“A Vice-presidência Financeira é a principal estrutura responsável pelas demonstrações financeiras, com suporte direto da Controladoria na elaboração dos documentos, a fim de garantir a adoção de boas práticas de controles interno."

AZUL S/A

Também foram evidenciadas vinculações da controladoria com a Diretoria, mais especificamente à Diretoria Financeira/Executiva. A partir de recortes, podem-se evidenciar as características principais referentes a esta vinculação, a saber: 
Emily Tavares Pessoa Maciel; Antônio André Cunha Callado.

"Subordinadas às Diretorias".

B2W - COMPANHIA DIGITAL

“A Diretoria Financeira - principal área responsável pelas demonstrações financeiras - conta com o suporte da Gerência de Contabilidade e Gerência de Controladoria"

GENERAL SHOPPING E OUTLETS DO BRASIL S.A.

\begin{abstract}
“A Diretoria Financeira - principal área responsável pela elaboração das demonstrações financeiras - conta com o suporte da área de Controladoria para sua elaboração, garantindo a adoção das boas práticas de controle interno e observação das normas contábeis aplicáveis."
\end{abstract}

LIQ PARTICIPAÇÕES S.A.

"Este Departamento reporta-se diretamente à Diretoria Financeira."

QUALICORP CONSULTORIA E CORRETORA DE SEGUROS S.A.

Resultados obtidos em pesquisas anteriores, tais como Nascimento e Reginato (2013), sugerem vinculação da controladoria à capacidade da alta administração das organizações a integrarem os gerentes e funcionários em torno dos objetivos fins das empresas, uma vez que o impacto da alta gestão é maior quando comparada ao contexto geral das organizações. Para Padoveze (2016) a controladoria, deve responder ao diretor ou vice-presidente administrativo e financeiro das empresas e exercer funções diferenciadas dos funcionários de níveis hierárquicos distintos.

Araújo (2003) aponta que a controladoria deve constar nas organizações hierarquicamente em nível da diretoria organizacional, pelo seu poder claro de tomada de decisão e frente às responsabilidades que lhes são cobradas. Esta perspectiva é corroborada por Beuren, Gomes e Luz (2012) que identificaram, dentre as 20 maiores empresas em faturamento da região Sudeste, quase metade (oito respondentes) tendo uma Diretoria como o órgão do qual a controladoria está vinculada.

Por outro lado, vinculações da controladoria à estrutura organizacional em níveis gerenciais também podem ser encontradas, mesmo entre empresas de grande porte e de capital aberto, como as empresas listadas na B3, a saber:

“A Companhia mantém em sua estrutura organizacional a área de controladoria, subordinada à Gerencia Administrativa".

ELECTRO ACO ALTONA S/A

Prosppectus - Perspectivas Qualitativas em Contabilidade e Organizações. João Pessoa. v. 1, n. 1, p. 57 $71, \mathrm{jul} / 2021$. 
Emily Tavares Pessoa Maciel; Antônio André Cunha Callado.

Bemfica e Callado (2018) também encontraram evidências de setores de controladoria posicionados no nível gerencial entre empresas de grande porte do setor sucroalcooleiro do Estado de Pernambuco.

Com relação à localização da informação, a partir da leitura dos conteúdos dos sítios institucionais e documentos de referência observou-se que uma parcela significativa, 184 das 220 empresas que externaram informações sobre a controladoria divulgadas nas fontes consideradas, foi localizada nos Formulários de Referência das empresas, como demonstra a tabela 1.

Tabela 1

Localização das informações da controladoria

\begin{tabular}{cc}
\hline & Frequência \\
\hline Formulário de Referência & 184 \\
Site e/ou Outros Relatórios & 36 \\
\hline & $\mathbf{2 2 0}$ \\
\hline
\end{tabular}

O Formulário de Referência é o documento que todas as empresas de capital aberto são obrigadas a enviar à Comissão de Valores Mobiliários, que fica à disposição do público em geral e conta com informações do emissor, como suas atividades, histórico na bolsa, fatores de risco, gestão da empresa, estrutura de capital, entre outros (Gelbcke, Santos, Iudícibus \& Martins 2018). Devido à importância e todas as informações constantes no Formulário de Referência, pode-se associar o uso de tal formulário, por parte das empresas, para externar detalhes sobre a controladoria.

Este achado, da localização das informações da controladoria, revela uma especificidade relevante acerca da forma pela qual informações sobre controladoria são divulgadas nos sítios institucionais das empresas listadas na B3. Uma vez que do Formulário de Referência são exigidas informações sobre o Controle dos riscos das empresas, bem como outros grupos de informações relevantes sobre aspectos estratégicos das empresas que, de maneira direta ou indireta, podem estar vinculadas a funções tipicamente vinculadas à controladoria, esta evidenciação sugere que os formulários de referência possuem importância significativa para a gestão de empresas de capital aberto.

Como alternativa ao Formulário de Referência, algumas empresas optaram por divulgar informações sobre controladoria em sítios institucionais. Também foram identificadas informações sobre controladoria em documentos institucionais disponibilizados nos sítios institucionais. Por exemplo, a empresa Movida Participações S.A. disponibiliza informações com relação à controladoria no corpo de seu relatório de sustentabilidade. Em outro exemplo ilustrativo, a empresa Andrade Gutierrez Participações S.A. disponibiliza informações sobre controladoria em seu relatório anual. 
Emily Tavares Pessoa Maciel; Antônio André Cunha Callado.

\section{CONCLUSÃO}

O debate sobre a controladoria é cada vez mais constante na literatura e na academia, apesar da ausência de conceituação unânime, inúmeros autores apontam quais as missões, funções e objetivos da controladoria no contexto organizacional. A controladoria vem ganhando espaço e se tornando importante para as organizações como um todo, auxiliando seus processos de gestão e otimizando metas e direcionamentos.

Porém, identificada a ausência de definições e alocações concretas da vinculação da controladoria e o local onde foram encontradas informações sobre a controladoria, essa pesquisa foi desenvolvida, de forma qualitativa para identificar entre as empresas que fazem parte da B3 a evidência de sua localização e de sua vinculação na estrutura organizacional a partir das informações divulgadas nos websites institucionais das empresas listadas.

Através das análises feitas, mesmo havendo pouca literatura na área, os achados da pesquisa corroboraram resultados anteriores sobre o local de vinculação da controladoria nas organizações, alta gestão, embora também tenham sido encontradas evidências acerca de vinculação no nível gerencial. Este achado amplia o entendimento apontado pela literatura sugerindo que sua vinculação no nível gerencial pode ser considerada como uma configuração plausível para controladoria como unidade organizacional.

Com relação ao local onde se encontram informações sobre a controladoria, os achados forneceram indícios relevadores, uma vez que até o momento, não havia estudos que apontassem onde tais informações vinham sendo divulgadas nos websites institucionais. Os achados desta pesquisa destacam relevância a ser atribuída aos formulários de referência, um documento completo, que é exigido de todas as companhias abertas, mas que não tem recebido grande atenção por parte de pesquisadores.

Inúmeras entidades reportaram o que a literatura traz sobre o fornecimento de indicadores, por parte da controladoria, para que haja a tomada de decisões por parte dos gestores das empresas, assegurando a qualidade e a integridade dos relatórios financeiros.

Não houve documentos completos que retratassem as informações sobre a controladoria, todas as informações que foram analisadas foram obtidas através de recortes de inúmeros documentos públicos de cada empresa, permitindo que concluamos que mesmo utilizando da controladoria, as organizações ainda não destinam um local específico para discorrer sobre as informações e detalhes pertinentes a controladoria. Ou seja, embora pontuada a importância da controladoria no contexto organizacional, pouco se encontra de detalhes sobre a controladoria no contexto organizacional. 
Emily Tavares Pessoa Maciel; Antônio André Cunha Callado.

Recomenda-se que futuras pesquisas possam investigar aspectos particulares da controladoria quando situada no nível gerencial e a maneira pela qual este posicionamento influencia suas funções. Outra oportunidade de pesquisas futuras está relacionada aos formulários de referência, seu processo de elaboração e a maneira pela qual as empresas o utilizam como documento institucional de divulgação de informações.

\section{REFERÊNCIAS}

Amorim, T. N. G. F., Oliveira, A. R. L., Manzi, S. M. S. \& Bemfica, M. F. C. (2018). Perfil e Competências do 'Controller' em Empresas no Recife. Revista Mineira de Contabilidade, 19(3), pp. 52-63. Recuperado de http://www.spell.org.br/documentos/ver/52067/perfil-e-competencias-do-controller--em-empresas-no-recife/i/pt-br.https://doi.org/10.21714/24469114RMC2018v19n3t05.

Anagusko, L. H., Araki, M. E. \& Moser, E. M. (2020). Implantação da Controladoria em Micro e Pequenas Empresas no Brasil: O que considerar?. Revista da Micro e Pequena Empresa. 14(1). $\quad$ pp. 59-78. Recuperado de http://www.spell.org.br/documentos/ver/57755/implantacao-da-controladoria-emmicro-e-pequenas-empresas-no-brasil--o-que-considerar-/i/pt-br. https://doi.org/10.6034/rmpe.v14i1.1256.

Araújo, R. C. De. (2003). A controladoria e a informação gerencial no processo decisório das empresas. Monografia (Especialização em Controladoria) - Universidade Federal da Paraíba. Paraíba, pp. 46.

Barreto, M. da G. (2008) Controladoria na gestão: a relevância dos custos da qualidade. São Paulo: Saraiva.

Bemfica, M. F. C. \& Callado, A. A. C. (2018). Relações entre características organizacionais e nível de sustentabilidade corporativa: um estudo nas empresas do setor sucroalcooleiro do estado de Pernambuco. Revista Eletrônica Sistemas \& Gestão, 13(2). Recuperado de https://doi.org/10.20985/1980-5160.2018.v13n3.1427

Bermudo, V. \& Vertamatti, R. (2016). Controladoria estratégica e seus desdobramentos comportamentais: a SOX como apoio à geração de valor organizacional, São Paulo: Atlas.

Beuren, I. M., Gomes, E. do C. O. \& Luz, R. M. Da. (2012). Motivações para implantar a Área Organizacional de Controladoria em Grandes Empresas. Gestão $\mathcal{E}$ Regionalidade, 28(82). https://doi.org/10.13037/gr.vol28n82.769.

Borinelli, M. L. (2006). Estrutura conceitual básica da controladoria: sistematização à luz da teoria e da práxis. Tese (Doutorado em Ciências Contábeis). Universidade de São Paulo, São Paulo. Recuperado de 
Emily Tavares Pessoa Maciel; Antônio André Cunha Callado.

https://www.teses.usp.br/teses/disponiveis/12/12136/tde-19032007-151637/ptbr.php

Callado, A. A. C. \& Amorim, T. N. G. F. (2017). Competências da Função de Controller em Hotéis de Grande Porte da Região Metropolitana do Recife. Revista Evidenciação Contábil \& Finanças, 5(2), pp. 57-73. Recuperado de https://periodicos.ufpb.br/ojs/index.php/recfin/article/view/28721. DOI:10.18405/recfin20170204.

Carraro, W. B. W. H.; Santanna, D. H. W. (2017). The Structure of Controllership Area in Organizations. Revista de Negócios, v. 22(2), pp. 23-33. Recuperado de http://www.spell.org.br/documentos/ver/49605/the-structure-of-controllershiparea-in-organizations-/i/pt-br.http://dx.doi.org/10.7867/1980-4431.2017v22n2p2333.

Coelho, E., Lunkes, R. J. \& Machado, A. O. (2012). A controladoria na hierarquia organizacional: um estudo nas maiores empresas do estado de Santa Catarina, Enfoque Reflexão Contábil, 31(2), pp. 33-46. Recuperado de http://www.spell.org.br/documentos/ver/41491/a-controladoria-na-hierarquiaorganizacional--um-estudo-nas-maiores-empresas-do-estado-de-santacatarina/i/pt-br. https://doi.org/10.4025/enfoque.v31i2.15490.

Frezatti, F., Rocha, W., Nascimento, A. R. \& Junqueira, E. (2009). Controle gerencial: uma abordagem da contabilidade gerencial no contexto econômico, comportamental e sociológico. São Paulo: Atlas.

Gelbcke, E. R., Santos, A. Dos., Iudícibus, S. De. \& Martins, E. (2018). Manual de contabilidade societária: aplicável a todas as sociedades: de acordo com as normas internacionais e do CPC. (3. ed.) São Paulo: Atlas.

Leite, E. G., Diehl, C. A. \& Manvailer, R. H. M. (2015). Práticas de Controladoria, Desempenho e Fatores Contingenciais: um Estudo em Empresas Atuantes no Brasil. Revista Universo Contábil, 11(2), pp. 85-107. Recuperado de http://www.spell.org.br/documentos/ver/37255/praticas-de-controladoria-desempenho-e-fatores-contingenciais--um-estudo-em-empresas-atuantes-nobrasil/i/pt-br. DOI:10.4270/RUC.2015213.

Leite, M.; Reif, E. \& Lavarda, C. E. F. (2018). Análise da Controladoria e suas Funções: Estudo de Caso em uma Organização da Construção Civil. Desafio Online, 6(1), pp. 1-24. Recuperado de https://periodicos.ufms.br/index.php/deson/article/view/2076

Lima, F. B. de L., De Luca, M. M. M., Santos, S. M. \& Ponte, V. M. R. (2011). A controladoria em Instituições Financeiras: Estudo de caso no Banco do Nordeste do Brasil SA. Revista Contabilidade Vista E Revista, 22(1), pp. 43-72. Recuperado de https://revistas.face.ufmg.br/index.php/contabilidadevistaerevista/article/view/595

Martins, G. De A. \& Theóphilo, C. R. (2016). Metodologia da investigação científica para ciências sociais aplicadas. (3a ed.) São Paulo: Atlas. 
Emily Tavares Pessoa Maciel; Antônio André Cunha Callado.

Morange, A. S. \& Jorge, F. T. (2008). Controladoria: análise financeira, planejamento e controle orçamentário. São Paulo: Atlas.

Nascimento, A. M. \& Reginato, L. (2013). Controladoria: um enfoque na eficácia organizacional. (3. ed.) São Paulo: Atlas.

Nascimento, A. M. \& Reginato, L. (2015). Controladoria: Instrumento de apoio ao processo decisório. (2. ed.) São Paulo: Atlas.

Nascimento, F. R. V., Rosa, A. L. T., Santos, S. M. D. \& Tenório, J. N. B. (2005). A Controladoria como suporte ao processo de gestão numa empresa do comércio varejista. Revista de Contabilidade do Mestrado em Ciências Contábeis da UERJ, 10(2), pp. 11-26. Recuperado de https://www.epublicacoes.uerj.br/index.php/rcmccuerj/article/view/5592

Padoveze, C. L. (2013). Controladoria Básica. 3. ed. São Paulo: Cengage Learning.

Padoveze, C. L. (2016). Controladoria estratégica aplicada: conceitos, estrutura e sistema de informações. São Paulo: Cengage Learning.

Peleias, I. R. (2002). Controladoria: gestão eficaz utilizando padrões. São Paulo: Saraiva.

Politelo, L., Guse, J. C., Leite, M., Silva, T. P. \& Dorr, A. C. (2014). Uma análise em organização sob a ótica da Controladoria Empresarial. Desafio Online, 2(1), pp. 487$504 . \quad$ Recuperado

de https://desafioonline.ufms.br/index.php/deson/article/view/1133

Schmidt, P., Santos, J. L. \& Martins, M. A. dos S. (2014). Manual de controladoria. São Paulo: Atlas.

Souza, A. J. de, Nobre, F. C., Padoveze, C. L. \& Calil, J. F. (2016). Controladoria na gestão de compras como estratégia na busca da eficiência e otimização do resultado econômico. Management Control Review, 1(1). Recuperado de http://www.journals.ufrpe.br/index.php/managementcontrolreview/article/view/1 040

Tambosi, S. S. V., Tambosi Júnior, J., Hein, N. \& Kroenke, A. (2021). Dimensões da Importância da Controladoria nas Organizações: Um Estudo Multivariado e Multicritério. Revista Contemporânea de Contabilidade, 18(46), pp. 3-15. Recuperado de https://periodicos.ufsc.br/index.php/contabilidade/article/view/58113. https://doi.org/10.5007/2175-8069.2021.e58113.

Tung, N. H. (2016). Controladoria financeira das empresas: uma abordagem prática: ampliado com metodologia de redução de custos. 10. ed. São Paulo: Edições Universidade-Empresa. 


\section{NOTAS}

Contribuição de Autoria

\begin{tabular}{|l|c|c|}
\hline Contribuição & $\begin{array}{c}\text { Emily Tavares Pessoa } \\
\text { Maciel }\end{array}$ & $\begin{array}{c}\text { Antônio André Cunha } \\
\text { Callado }\end{array}$ \\
\hline 1. Definição do problema de pesquisa & $\mathrm{X}$ & $\mathrm{X}$ \\
\hline $\begin{array}{l}\text { 2. Fundamentação Teórica/Revisão de } \\
\text { Literatura }\end{array}$ & $\mathrm{X}$ & $\mathrm{X}$ \\
\hline $\begin{array}{l}\text { 3. Definição dos procedimentos } \\
\text { metodológicos }\end{array}$ & $\mathrm{X}$ & $\mathrm{X}$ \\
\hline 4. Coleta de dados & $\mathrm{X}$ & $\mathrm{X}$ \\
\hline 5. Análise e interpretação dos dados & $\mathrm{X}$ & $\mathrm{X}$ \\
\hline 6. Revisão crítica do artigo & $\mathrm{X}$ & $\mathrm{X}$ \\
\hline 7. Escrita do artigo & $\mathrm{X}$ & \\
\hline 8. Outros (especificar) & & \multicolumn{2}{|c|}{} \\
\hline
\end{tabular}

\section{Editores}

Editora Geral: Viviane da Costa Freitag

Editora Adjunta: Karla Katiuscia Nóbrega de Almeida

\section{Histórico}

Recebido em: 12/07/2021

Revisado por pares em: 16/07/2021

Reformulado e recomendado para publicação: 19/07/2021

Publicado em: 30/07/2021

Prosppectus - Perspectivas Qualitativas em Contabilidade e Organizações. João Pessoa. v. 1, n. 1, p. 57 $71, \mathrm{jul} / 2021$. 